\title{
Prevalence of HHV-8 Antibodies among HIV Infected Patients
}

\author{
Bob Agwu Ukonu \\ University of Abuja Teaching Hospital, Gwagwalada, Abuja, Nigeria \\ Tel: 234-805-791-5902; 234-702-675-1965Ｅ-mail: bobify@yahoo.com \\ Emeka U. Eze \\ University of Benin Teaching Hospital, Benin City, Edo State, Nigeria
}

Received: October 26, 2010 Accepted: November 19, 2010 doi:10.5539/gjhs.v3n1p185

\begin{abstract}
Background: There is a widespread believe that the seroprevalence of HHV-8 in HIV infected persons are higher than the general population. This study seeks to found out the seroprevalence of HHV-8 antibodies among HIV infected patients in Edo State, South- South Nigeria.

Materials and Method: The sera of HIV infected and non HIV infected persons were tested with double ELISA (Genscreen ultra HIV Ag-Ab ELISA and JN HIV-1/2 ELISA KIT) for HIV screening and HHV-8 testing was done using Advanced Biotechnology Incorporated ELISA for HHV-8 IgG antibody detection.

Results: The antibodies for HHV-8 was positive in $126(70 \%)$ of 180 recruited for the study. The HIV positive study group were 100 out of which 87 (87\%) were positive for HHV-8 antibodies. The sero-positivity of HHV-8 among the $80 \mathrm{HIV}$ negative control group was 39 (48.8\%). There was statistically significant association between HIV and HHV-8 at $\mathrm{P} \leq 0.0001$. The odds Ratio OR of 7.04 at $95 \%$ CI (3.21- 15.64) indicates that HHV-8 positivity is more in HIV infected persons than those who were HIV negative. The relative risk ratio RR of $1.74 ; 95 \% \mathrm{CI}(1.14-2.26)$ also indicates that those with HIV infection are at a higher risk of acquiring HHV-8 infection.

Conclusion: There is a high seroprevalence of HHV-8 antibodies among people living with HIV/AIDS. This may not be in connection with route of transmission when compared to similar studies carried out by other researches in Africa.
\end{abstract}

Keywords: HHV-8, HIV patients

\section{Introduction}

The new human herpesvirus called human herpesvirus type 8 (HHV-8), was found as DNA fragments by molecular techniques (Chang Y, 1994). After the isolation of the HHV-8 virus, it was characterized. Serological tests were developed and that allowed studies to be carried out to ascertain the prevalence of infection with HHV-8 and regions with high prevalence of HHV-8 infection reflected Kaposi's sarcoma and HIV epidemiology (Lennette ET, 1996). It was discovered that in patients infected with HIV and in some geographical regions that HHV-8 was associated with high risk sexual practices and that the virus was probably sexually transmitted (Melbye M, 1998; Mbulaiteye SM, 2003).

Sexual transmission of HHV-8 infection was entertained by the finding of viral practices in the semen and prostrate organs of infected individuals (Monini p, 1996). HHV-8 rout of transmission is not well understood. Although early epidemiological studies implicated sexual transmission in homosexuals, recent studies indicate that HHV-8 DNA is detected more commonly in saliva than in genital secretions (Pauk J, 2000). In regions where HHV-8 infection is endemic, horizontal infection appears likely (Gessain A, 1999).

There is a reciprocal interaction between HIV and HHV-8. Studies have shown that their routes of transmission, risk factors for infection, type of cells infected and pathogenesis are and intricately related and interposed (Corey Casper, 2006; Viejo Borbolla A, 2003; Gallo R, 1998).

The seroprevalence of HHV-8 infections approximately mirrors the prevalence of Kaposi's sarcoma which is the most common neoplastic events seen in HIV infected patients. This study was informed by the paucity of reports 
on human herpes virus 8 infections in Nigeria. This study seeks to find the prevalence of HHV-8 antibodies in HIV infected persons.

\section{Materials and Method}

\subsection{Study Area/Site}

This study was carried out in the out-patient and in-patient units of the Department of medicine in University of Benin Teaching Hospital (UBTH) Benin City Edo State from June 2007-May 2008, with age range from 15 years and above. The Dermatology/ Venereology unit in the Department of Medicine of UBTH takes care of sexually transmitted infections including HIV/AIDS referred from hospitals within Edo State, Delta State, Kogi State, Ondo State, Ekiti and Anambra State.

A control group who were HIV negative (hospital workers and apparently patients' healthy relatives) were included in the study. A total of 180 consecutive specimens were tested using two screening assay for HIV test, JN-HIV $1 / 2$ ELISA KIT (Jeeri- Neotech International Medical Incorporated, USA) and GENSCREEN Ultra HIV Ag- Ab ELISA. (Catalog No: 72388 Bio- RAD- France). All samples for the subjects were reactive on both assays and were considered positive for HIV whereas all the samples for controls were negative.

The sera were further evaluated for the presence of antibodies specific for HHV-8 using solubilised HHV-8 whole virus extract prepared and standardized at the Advanced Biotechnology Incorporated ELISA for human herpesvirus-8 (HHV-8) IgG antibody detection. Catalog No.15-501-000. The cut-off value for each serum was obtained by averaging the three negative controls wells reading and multiplying the result by 3 . The optical density OD for each well was gotten by dividing the reading of each sample well by the cut-off.

Negative samples were $\leq 0.75$

Positives samples were $\geq 1.00$

Equivocal (Borderline) 0.76- 0.99

Quality control was ensured by making sure that positive control wells optical density readings were $\geq 0.300$ and all the three negative control wells had optical density readings $\leq 0.100$

\section{Results}

The antibodies to HHV-8 was positive in $126(70 \%)$ of the 180 samples tested. In this study, we examined and tested the sera of $100 \mathrm{HIV}$ infected patients and 87 (87\%) tested positive to antibodies to the HHV-8 infection, while $39(48.8 \%)$ of the 80 control subjects tested positive to antibodies of HHV-8 infection. See table 1

In spite of the high percentage of HHV-8 positive status for those between 34-64 years, p-value of 0.42 shows that there was no statistical relationship between HHV-8 and age. Linear trend was 0.320 and $p>0.05$ suggests that there was no linear association between HHV-8 and age (see table 2). However, the difference between those who were HHV-8 positive and HHV-8 negative of the different age groups except those between age group 15-24 years were statistically significant. This result shows that age is a confounding variable. The difference between males and females that were HHV-8 positive and those that were HHV-8 negative respectively was statistically significant $(\mathrm{p}<0.005)$. However, when gender was compared with HHV-8 the differences were not statistically significant and p-value was 0.145 (see table 3 ). This result also shows that sex is a confounding variable.

\section{Discussion}

The success of HHV-8 infection has been linked to immune evasive strategies and also to the ability to down-regulate immune response (Rezaee JA, 2006). Similar to the effects of HIV on CD4 T- cell cytokines, HHV-8 (via v-MIPS) can unfavourably polarize the adaptive, immune response towards a predominant TH2 humoral type of CD4 T- cell response (Rezaee JA, 2006).

The seroprevalence of HHV-8 antibodies is about $15-50 \%$ higher in HIV positive patients than in HIV negative individuals of the same population (Chatlynne LG, 1999; Ablashi DV, 1999). In east and central Africa HHV-8 prevalence in adults was reported to be 70-90\% (Sonja J. Olsen, 1998; Engels EA, 2000). The above findings are comparable with our study where we had $70 \%$ for all the subjects and $87 \%$ in the HIV infected population and $48.8 \%$ in the HIV non-infected population. The difference between the HIV positive study group and the HIV negative control group was statistically significant with $\mathrm{X}^{2}$ of 30.94 and a $\mathrm{p}<0.0001$.

Previous studies in Nigeria had shown a prevalence of $34 \%$ and $42 \%$ for women and men that had STDs and HIV respectively in Lagos (Eltom MA, 2000) as against 33\% and 31\% for women and men in general population in the same study (Eltom MA, 2000). The role of HIV in the aetio- pathogenesis of the HHV-8 infection may be 
independent of its immunosuppressive ability. It can promote transmission of HHV-8 by increasing mucosal shedding of the virus, reactivating lytic replication through the effects of HIV-1 Tat protein and cytokines (IL-1, oncostatin M, IL-6 and interferon $\ulcorner$ ) in inducing a switch from latent to lytic infection and also facilitate progression of HHV-8 infection of Kaposi's sarcoma (Galavan M, 2001). This may explain why those with HIV infection have higher predilection to having HHV-8 antibodies than the HIV negative control group.

Other studies had implicated age as a predictor to acquisition of HHV-8 antibodies (Sonja J. Olsen, 1998; Gao SJ, 1996). However, our study did not show any statistically association between age and HHV-8 acquisition. Probably other factors involved in the transmission of HHV-8 infections as individuals increased in age might not have been considered in this study.

The relationship between HHV-8 antibodies and sex was not statistically significant. This confirms the work of Sonja et al in Zambia were sex was found not to have any relationship in acquisition of HHV-8 infection (Sonja J. Olsen, 1998). However, Eltom et al in Lagos had found HHV-8 to be twice more common in males than in females when those females involved in commercial sex work were excluded. Such variable was not isolated in this study, rather all variables were considered in arriving at a conclusion.

Finally, the greatest danger of HHV-8 infection in HIV infection is its ability to potentiate or induce neoplasm especially Kaposi's sarcoma. Moore et al reported that approximately one third of individuals who previously with HHV-8 antibodies develop Kaposi's sarcoma within 10 years of infection with HIV (Gao SJ, 1996).

\section{Conclusion}

In conclusion, the high prevalence of HHV-8 antibodies among people living with HIV/AIDS in this study is a wakeup call for healthcare providers in Nigeria considering the teaming population living with HIV/AIDS in our country. However, a large scale multi-centre screening of HHV-8 among people living with HIV would be a welcome development if this tide is to be check-mated in the future.

\section{References}

Ablashi DV, Chatlynne H, Cooper N, Thomas D, Yadua M, Nonrandom M, et al. (1999). Seroprevalence of HHV-8 infection in countries of South East Asia compared to United States: the Carribean and Africa. British Journal of Cancer, 81:893-897.

Chang Y, Cesarman E, Pessin MS et al. (1994). Identification of herpesvirus- like DNA sequences in AIDS-associated Kaposi's sarcoma. Science, 4: 1865-1869.

Chatlynne LG, Ablashi DV. (1999). Seroepidemiology of KSHV. Cancer Biology, 9: 175-185.

Corey Casper. (2006). HHV-8, KS and AIDS associated neoplasm. In HIV insite.com (Reviewed January, 2006).

Eltom MA, Mbuylaiteye SM, Dada AJ, Whitby D, Biggar RJ et al. (2002). Transmission of human herpesvirus-8 by sexual activity among adults in Lagos, Nigeria. AIDS, Dec. 6; 16(18): 2473-2478.

Engels EA, Sinclair MD, RJ, Whitby D, Ebbesen P, Grodert JJ, Gastwirth JL. (2000). Latent class analysis of human herpesvirus-8 Assay performance and infection prevalence in Sub-Saharan Africa and Matta. International Journal of Cancer, 88:1003-1008.

Galavan M, Cassae E, Di Luca D. (2001). HHV-8 (KSHV) ORF 50 interacts synergically with tat gene product in trans-activating the HIV-1 long terminal repeats. Journal of Genral Virology, 82: 1965-1970

Gallo R. (1998). Some aspects of the pathogenesis of HIV-associated Kaposi's sarcoma. Journal of the National Institute Monographs, 23: 55-57.

Gao SJ, Kingsley L, Hoover DR, Spira TJ, Ronaldo CR, Saah A. et al. (1996). Seroconversion to antibodies against KSHV related nuclear antigens before the development of Kaposi's sarcoma. New England Journal of Medicine, 335:233-241.

Gessain A, Mauclere P, Van Beveren M, et al. (1999). Human herpes 8 primary infection during childhood in Cameroon, Central Africa. International Journal of Cancer, 81: 189-192.

Lennette ET, Backbrurn DJ, Levy JA. (1996). Antibodies to human herpesvirus 8 in general population and Kaposi's sarcoma. Lancet, 348: 858-861.

Mbulaiteye SM, Pfeiffe RM, Whitby D, Brubaker GR, Shao J, Briggar RJ. (2003). Human herpes-8 infection within families in rural Tanzania. The Journal of infectious disease, 187 (11): 1780-1785. 
Melbye M, Cook PM, Hjalgrim H, et al. (1998). Risk factors for Kaposi's sarcoma-associated herpesvirus (KSHV/HHV-8) seropositivity in a cohort of homosexual men. International Journal of Cancer, 77:543-548.

Monini p, Lellis L, Fabre M, et al. (1996). Kaposi's sarcoma-associated herpesvirus DNA sequence in prostrate tissue and human semen. New England Journal of Medicine, 334:1168-1172.

Olumide YM, Dada AJ, Sogbanmu IB, Aruna GA. (1997). Seroprevalence study of HIV-I, HIV-II and HTLV-1 among patients at the Dermatovenerology clinic of Lagos University Teaching Hospital. International Journal of Dermatology, 36: 741-744.

Onunu AN, Eze EU, Okoduwa C, Kubeyinje PE, Adeyekun A, Scwartz RA. (2007). The Increasing prevalence of Kaposi's sarcoma in HIV infected persons. International Journal of Dermatology March, 46 (3): 264-267

Pauk J, Huang ML, Brodie SJ, Wald A, Koelle DM, Schacker T, Celum C, Selke S, Corey L. (2000). Mucosal shedding of human herpesvirus 8 in men. New England Journal of Medicine, 343: 1369-1377.

Rezaee JA, Cunningham C, Davidson A, and Blackbourn D. (2006). Kaposi's sarcoma associated herpesvirus immune modulation; an overview. Journal General Virology, 87: 1781-1804.

Sonja J. Olsen, Yang Chang, Patricks Moore, Robert J, Biggar and Madsmelbye. (1998). Increasing Kaposi's sarcoma- associated herpesvirus-8 seroprevalence with age in highly Kaposi's sarcoma endemic region, Zambia in 1983. AIDS, 12: 1921-1925.

Viejo Borbolla A, Schutz T. KSHV. (2003). Key aspects of epidemiology and pathogenesis. AIDS Rev. 5: 222-229.

Table 1. Prevalence of Hhv-8 Antibodies among HIV Infected Patients

\begin{tabular}{|l|l|l|l|l|l|l|l|}
\hline & HHV- $^{+}$ & HHV-8 $^{-}$ & Total & prevalence(\%) & odds & $\mathrm{X}^{2}$ & P-value \\
\hline HIV + & 87 & 13 & 100 & 87 & 6.69 & 30.964 & $0.0001^{* *}$ \\
\hline HIV - & 39 & 41 & 80 & 48.8 & 0.95 & & \\
\hline Total & 126 & 54 & 180 & & & & \\
\hline
\end{tabular}

Note for all the tables: $\mathrm{RR}=$ Relative risk Ratio; ${ }^{*}$ Difference is not statistically significant; $* *$ Difference statistically significant; $\mathrm{RR}=$ Relative Risk Ratio; $\mathrm{OR}=$ Odds ratio

Table 2. Relationship between age groups and HHV-8 antibodies

\begin{tabular}{|l|l|l|l|l|l|l|l|l|}
\hline Age group & HHV-8+(\%) & HHV-8-(\%) & TOTAL & $\mathbf{X}^{\mathbf{2}}$ & d.f & P-value & OR & Log Odds \\
\hline $\mathbf{1 5 - 2 4}$ & $3(50)$ & $3(50)$ & 6 & 0.00 & 1 & $1.00^{*}$ & 1.00 & 0 \\
\hline $\mathbf{2 5 - 3 4}$ & $35(66)$ & $18(34)$ & 53 & 5.45 & 1 & $0.018^{* *}$ & 1.94 & 0.287 \\
\hline $\mathbf{3 5 - 4 4}$ & $47(68.1)$ & $22(31.9)$ & 69 & 9.05 & 1 & $0.007^{* *}$ & 2.14 & 0.330 \\
\hline $\mathbf{4 5 - 5 4}$ & $27(81.2)$ & $6(18.2)$ & 33 & 13.36 & 1 & $0.0009^{* *}$ & 4.50 & 0.653 \\
\hline $\mathbf{5 5 - 6 4}$ & $14(73.7)$ & $5(26.3)$ & 19 & 4.26 & 1 & $0.04^{* *}$ & 2.80 & 0.447 \\
\hline Total & $126(70)$ & $54(30)$ & 180 & & & & & \\
\hline $\begin{array}{l}\text { Overall } \mathbf{X}^{\mathbf{2}} \\
\mathbf{X}^{\mathbf{2}} \text { for Linear trend }=0.320\end{array} \quad$ P-value $=0.422^{*} ;$ & d.f $=4$ \\
\hline
\end{tabular}

Table 3. Relationship between Sex and HHV-8

\begin{tabular}{|l|l|l|l|l|l|l|l|}
\hline SEX & HHV-8 $^{+}(\%)$ & HHV-8 $^{-}(\%)$ & Total & $\mathbf{X}^{\mathbf{2}}$ & d.f & Odds & P-value \\
\hline Male & $67(75.3)$ & $22(24.7)$ & 89 & 22.753 & 1 & 3.0455 & $0.000^{* *}$ \\
\hline Female & $59(64.8)$ & $32(35.2)$ & 91 & 8.018 & 1 & 1.844 & $0.0015^{* *}$ \\
\hline Total & $126(70)$ & $54(30)$ & 180 & & & & \\
\hline
\end{tabular}

Overall $\mathbf{X}^{2}=2.33$; d.f $=1$; P- value $0.145^{*}$; OR $=3.0455 / 1.844=1.65 ; 95 \%$ CI $(0.83<\mathrm{OR}<3.32)$; Relative Risk ratio $\mathrm{RR}=1.16 ; 95 \% \mathrm{CI}(0.96<\mathrm{RR}<1.41)$ 